\title{
Digital medicine technologies for pre-trip medical examination of drivers
}

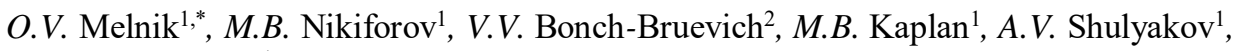 \\ and D.I. Ustyukov ${ }^{1}$ \\ ${ }^{1}$ Ryazan State Radio Engineering University named after V.F. Utkin, Gagarina str., 59/1, Ryazan, \\ 39005, Russia \\ ${ }^{2}$ NEUROCOM, Bolshaya Pochtovaya str., 39, build. 1, Moscow, 111250, Russia
}

\begin{abstract}
The technologies of automation of pre-trip integrated examination of the drivers' conditions are considered, which make it possible to significantly improve the quality of control while reducing the time for its passage. A comparative analysis of known analogues is carried out, problems are formulated, the solution of which will increase the diagnostic efficiency of telemedicine examination. The configuration of the developed computer control system and the hardware-software structure of the subject's control panel are described. The ways of increasing the reliability of user identification are considered. Technical means have been developed for non-contact thermometry and assessment of tremor parameters. Algorithms for assessing the physiological and psychoemotional state of drivers have been implemented.
\end{abstract}

\section{Introduction}

Statistical studies in the overwhelming majority of countries [1] speak of an ever-growing number of traffic accidents caused by poor driver health, intoxication, and fatigue. According to the requirements of the Ministry of Health of the Russian Federation [2], it is necessary to carry out medical control of the condition of drivers of public and commercial transport before each trip. In addition, it is required to accumulate statistical information about the health status of the driver, carry out its analysis, which will provide the ability to predict and prevent critical situations. Therefore, the problem of creating and implementing automated pre-trip control systems is very relevant and consistent with Russian [3] and global [4] trends in the digitalization of healthcare.

\section{Experience in creating automated systems for pre-trip control of drivers}

In most countries, the main control is carried out only over the observance of the driver's work and rest regime with the help of additional systems installed in the vehicle. Pre-trip control is not provided, and drivers are independently responsible for their health [5]. In the

\footnotetext{
*Corresponding author: omela111@yandex.ru
} 
Russian Federation, there are specially developed conditions for such a procedure as a medical examination of drivers. The pre-trip examination is carried out in accordance with the order of the Ministry of Health of 15.12.2014 No. 835n "On approval of the Procedure for conducting pre-shift, pre-trip and post-shift, post-trip medical examinations" [2] immediately before departure, after receiving the waybill.

If, during the pre-trip medical examination (in the absence of inflammatory diseases, as well as data on a previous increase or decrease in blood pressure), there are abnormalities in the work of the driver's cardiovascular system (blood pressure and others), characteristic changes in the color of the skin, conjunctivas, scleras, narrow or wide pupils (inadequate to lighting), a weak or absent reaction of the pupils to light, as well as deviations in behavior, impaired walk and speech, tremors of the fingers, eyelids, the smell of alcohol from the mouth, then a medical worker is obliged to conduct a sobriety control for such a driver.

The following health deviations are grounds for dismissal of drivers of motor vehicles from work:

- the presence of symptoms of an acute illness or an exacerbation of a chronic illness (fever over $37^{\circ} \mathrm{C}$, complaints of poor health, general weakness, headache and toothache, acute eye diseases, pain in the ear, chest or abdominal cavity, etc.);

- an increase or decrease in heart rate and changes in blood pressure above or below levels characteristic of the driver being examined;

- being under the influence of alcoholic beverages or other means (narcotic and psychotropic drugs or toxicants) that violate the functional state.

For drivers with hypertension, an individual blood pressure rate is determined based on the results of measurements in at least 10 pre-trip examinations, and admission to work is carried out strictly individually on the recommendation of their attending physician.

Thus, the basic measured parameters of pre-trip control include:

body temperature;

alcohol content in the exhaled air;

blood pressure;

heart rate.

Russia is the world leader in the development, production and implementation of automated systems for pre-trip driver examination. Table 1 provides a partial list of the most common systems.

The systems considered in Table 1 belong to the class of telemedicine, i.e. their use does not provide for the direct interaction of the person undergoing the examination with the medical personnel. Despite the obvious advantages of automated research, the following series of problems can be identified that reduce the reliability of the assessment of the driver's condition.

For any telemedicine system, the issue of user identification is critical. In most automated systems, identification of the driver undergoing examination is carried out by entering a personal code or by using individual magnetic carriers. In addition, a number of systems provide for photo/video recording of the examination process or transmission of a video stream of the examination procedure to the screen of a medical worker's computer. However, such identification methods do not exclude violations on the part of drivers, when, for example, a driver who doubts his own state of health (high blood pressure, residual alcohol in the blood, etc.) may ask another person to undergo an examination "for himself". Therefore, it is relevant to create video computer technologies for identifying the identity of the user of an automated system.

Self-use by the driver of standard non-contact thermometers, which are part of most systems, can often lead to false negative results in the case of an elevated body temperature. This is due both to the physiological characteristics of the organism, which has different temperatures in different areas, and with a high probability of carrying out the procedure of 
self-measurement incorrectly. This requires the creation of new technical means that increase the accuracy of temperature measurement.

Table 1. Characteristics of pre-trip driver examination systems. Features: 1 - Measurement of blood pressure; 2 - The presence of a breathalyzer; 3 - Camera for photo / video recording; 4 - Temperature measurement; 5 - Pulse measurement; 6 - The presence of a built-in printer; 7 - Identification using magnetic or contactless carrier; 8 - Identification of signs of arrhythmias; 9 - Computer testing of psychological state.

\begin{tabular}{|c|c|c|c|c|c|c|c|c|c|c|}
\hline \multirow{2}{*}{ Name, manufacturer } & \multicolumn{9}{|c|}{ Capabilities } & \multirow{2}{*}{ Additional characteristics } \\
\hline & 1 & 2 & 3 & 4 & 5 & 6 & 7 & 8 & 9 & \\
\hline $\begin{array}{l}\text { SafeOperator hardware and } \\
\text { software complex (HSC) } \\
\text { JSC "TECHNOLOGIYA } \\
\text { ZDOROVYA" (Russia, } \\
\text { Moscow) https://safe- } \\
\text { operator.ru/ }\end{array}$ & + & + & + & + & + & + & + & - & - & $\begin{array}{l}\text { Monoblock or PC with display } \\
\text { Unified body } \\
\text { Dimensions: } 250 \times 350 \times 370 \\
\text { Weight: } 10 \mathrm{~kg}\end{array}$ \\
\hline $\begin{array}{l}\text { AMCS - an automated } \\
\text { medical control system. } \\
\text { CyberSystems Group of } \\
\text { Companies (Russia, } \\
\text { Moscow) http://cbrss.ru/ }\end{array}$ & + & + & + & + & - & - & + & - & - & $\begin{array}{l}\text { Uninterruptable power source } \\
\text { PC } \\
\text { Wi-fi module } \\
\text { Touch screen } \\
\text { LTE modem }\end{array}$ \\
\hline $\begin{array}{l}\text { ESME - electronic system } \\
\text { of medical examinations } \\
\text { KVAZAR LLC } \\
\text { (Kazakhstan, Nur-Sultan) } \\
\text { https://esmohse.kz/ }\end{array}$ & + & + & - & + & + & + & - & + & + & $\begin{array}{l}\text { Vandal resistant terminal } \\
\text { PC with two monitors for the } \\
\text { doctor's workplace } \\
\text { Formation of an electronic } \\
\text { journal } \\
\text { Integration with related } \\
\text { systems (SAP, Oracle, } 1 \mathrm{C} \text {, } \\
\text { etc.) }\end{array}$ \\
\hline $\begin{array}{l}\text { PAC "Telemedic" - pre-trip } \\
\text { medical examination } \\
\text { NPF Ecotechprom LLC } \\
\text { (Russia, Ufa) } \\
\text { http://tvmedic.ru/ }\end{array}$ & + & + & + & + & + & + & - & - & - & $\begin{array}{l}\text { Transferring the results of the } \\
\text { medical examination to the } \\
\text { server }\end{array}$ \\
\hline $\begin{array}{l}\text { Medical complex } \\
\text { "KODOS" } \\
\text { Biosoft-M (Russia, } \\
\text { Moscow) } \\
\text { http://www.biosoft-m.ru/ }\end{array}$ & + & + & + & + & + & + & + & - & - & $\begin{array}{l}\text { The choice of the type of } \\
\text { medical examination: pre-trip, } \\
\text { pre-shift, post-trip, post-shift } \\
\text { Lung examination - arterial } \\
\text { oxygen saturation } \\
\text { Transfer of a medical report to } \\
\text { a mobile device } \\
\text { Keeping of journals of medical } \\
\text { reports }\end{array}$ \\
\hline $\begin{array}{l}\text { Portable complex for the } \\
\text { automation of medical } \\
\text { examinations "STRAZH" } \\
\text { Biosoft-M (Russia, } \\
\text { Moscow) } \\
\text { http://www.biosoft-m.ru/ }\end{array}$ & + & + & + & + & - & - & - & - & - & $\begin{array}{l}\text { Dimensions: } 170 \times 130 \times 80 \mathrm{~mm} \\
\text { Weight: } 486 \mathrm{~g} \\
\text { Power supply from a } \\
\text { stationary source or from the } \\
\text { "cigarette lighter" in the car } \\
\text { cab } \\
\text { Bluetooth channel } \\
\text { Telemedicine consultations } \\
\text { Keeping electronic journals of } \\
\text { medical examinations, } \\
\text { automatic generation of } \\
\text { electronic protocols }\end{array}$ \\
\hline $\begin{array}{l}\text { DIMECO terminal } \\
\text { DIMECO (Russia, } \\
\text { Moscow) } \\
\text { https://www.dimeco.ru/ }\end{array}$ & + & + & + & + & + & + & + & - & - & $\begin{array}{l}\text { Online health report } \\
\text { Keeping a log book in } \\
\text { electronic form }\end{array}$ \\
\hline
\end{tabular}


Despite the fact that there is a breathalyzer in all the systems under consideration, which allows assessing the concentration of ethanol vapors in the exhaled air, today there are almost no automated solutions for detecting intoxication with other psychoactive substances. The creation of methods and means for the indirect detection of signs of the effects of narcotic and psychotropic drugs that violate the functional state is a necessary component of increasing the reliability of the examination.

The lack of direct contact with the doctor does not allow tracing the signs of a general impairment of the driver's condition associated with overwork, stress, pain syndrome and other factors. Remote observation of the subject using a video camera does not fully reflect his condition, and in a number of systems, video recording is not provided. Accordingly, it is necessary to use complex indicators of the functional and psychoemotional state of the driver, for example, based on the parameters of heart rate variability, whose deviation from the norm is a recommendation for not allowing the driver to work and an indication for additional examination.

Thus, the analysis of the capabilities of the analogs of the developed system allows concluding: to improve the quality and completeness of the survey, and, consequently, to reduce the accident rate on the roads, it is necessary to expand the functionality of the systems.

\section{Development of an automated system for pre-trip examination}

To select and detail the description of the optimal system architecture, it was required to solve the following series of problems.

- Study the range of medical measuring equipment and components for basic measuring devices (blood pressure, pulse, temperature, alcohol content in exhaled air). Conduct a comparative analysis of the accuracy characteristics, ergonomics and applicability of using different types of devices within the system.

- Study and conduct comparative analysis of methods and tools for the implementation of additional research.

- Determine the requirements for the system from the standpoint of the information content of the study, the time spent on the study, feasibility and scalability. Select and justify the basic system architecture based on them.

- Identify the main components of the system and the ways of their interaction, as well as propose solutions that can be used as fundamental for the design work.

We have developed an automated system for mass pre-trip examination of public transport drivers. The system provides the ability to simultaneously connect to a personal computer of a medical worker from one to fifty devices for automated registration and assessment of a set of physiological indicators of drivers - test subjects' panels. The general structure of this panel is shown in Figure 1.

The measuring subsystem of the subject's panel is implemented on the basis of the peripheral microcontroller PIC24FJ64GC006. Reception of request and control commands from the central controller and transmission of measurement information to the central controller is carried out using the UART interface. A client-server application was developed that provides data transmission from the subject's control panel to the doctor's personal computer for displaying and recording information into the database.

Figure 2 shows the process of testing the model of the test subject's panel of the automated system. After carrying out the procedure for identifying the user's identity, a sequence of instructions is displayed on the touch screen for the driver to independently go through various stages of registering his physiological indicators - measuring blood pressure and pulse, thermometry, monitoring alcohol vapors in exhaled air, etc. After completing the full cycle of studies, the doctor's computer receives detailed information 
about all the examination results, and the user is given brief instructions on his further actions on the touchscreen display of the test subject's control panel (permission or refusal to start the shift, referral for additional examination).

The developed system is software scalable - depending on the requirements of the customer organization, a different set of procedures can be included in the full examination cycle of the test subject's control panel, the combination of which can be configured from the personal computer of the medical worker. For example, a test procedure for a sensorimotor reaction and concentration of attention is programmatically implemented in the subject's control panel, which can be either added to the examination cycle or excluded from it, depending on the restrictions on the time of the study.

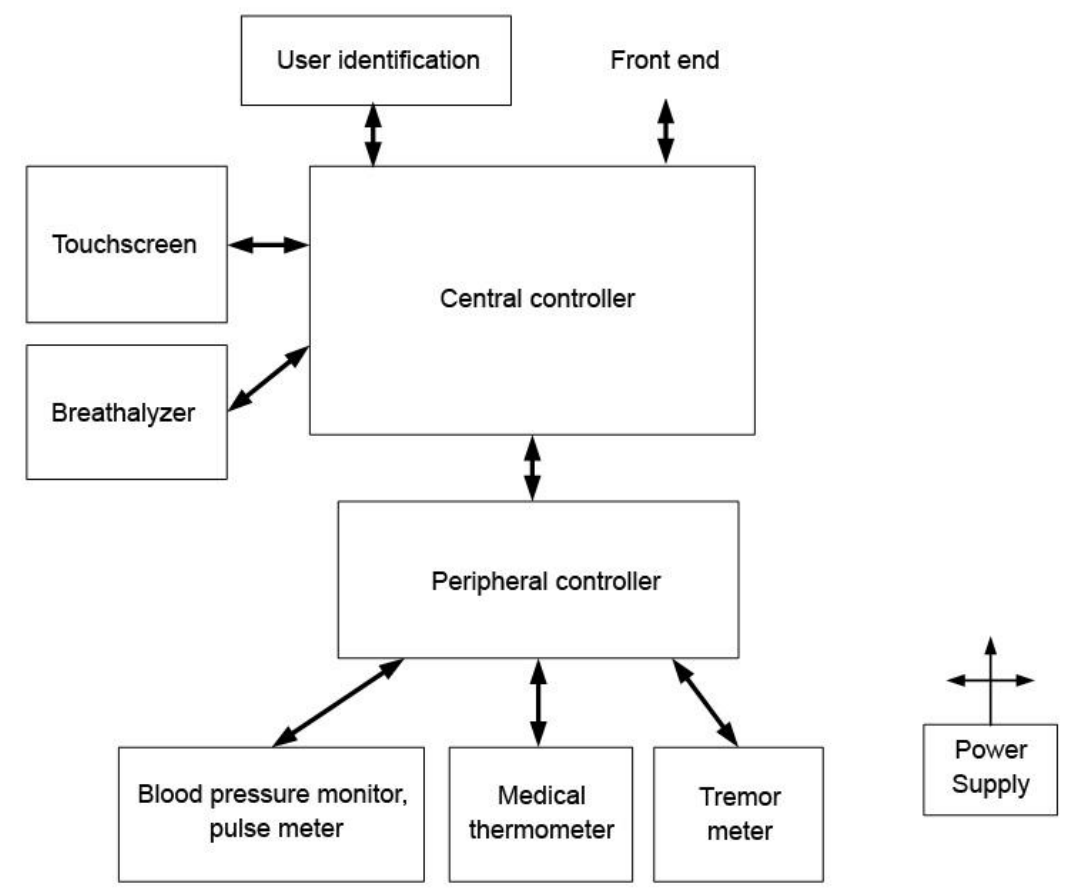

Fig. 1. Block diagram of the test subject's panel of the pre-trip control system.

Basic algorithms for the interpretation of physiological parameters implement standard procedures for assessing physiological conditions, for each of which the driver cannot be allowed to the work shift:

- a critical increase or decrease in blood pressure [6];

- the presence of alcohol vapors in the exhaled air;

- increased body temperature;

- the presence of signs of arrhythmia.

However, to ensure a full approximation of the diagnostic efficiency of telemedicine examination to the efficiency of the procedure of direct interaction with a doctor, it is necessary to solve a number of problems formulated in Section 2. Let us consider the selected ways of solving the problems of increasing the efficiency of an automated diagnostic system in more detail. 


\subsection{Driver identification}

The developed system provides for two standard procedures for driver identification - by entering a personal code on the touch screen, using individual magnetic cards, or a combination of these. The identification unit also includes a video camera that allows streaming the image of the examination procedure on the screen of a medical worker's computer.

Algorithms for processing video images were developed that allow real-time detection of the driver's face and recognize his actions and facial expressions [7, 8], which will allow not only one-time identification of the user "by the face" [9] for admission to work with the system, but also control of the passage of the examination procedure by the very person for whom the admission was allowed.

\subsection{Temperature measuring channel}

Analysis of possible ways of measuring temperature to determine the individual indicators of the pre-trip functional state of the driver made it possible to conclude that the noncontact method of measurement is preferable. The main advantages of this method are the absence of the need for disinfection of the meter, as well as the high speed of temperature measurement in comparison with contact thermometers.

However, a study of the market for non-contact temperature meters confirmed the impossibility of using ready-made devices within the system. To create a temperature measurement channel, the choice was made towards digital temperature sensors of the MLX90614 series. The MLX90614 sensor is an intelligent infrared thermometer, contains a low noise analog signal amplifier, 17-bit ADC and DSP controller, such a composition allows for high accuracy measurements.

During the prototyping, two design options were considered using a tube with a diameter of $20 \mathrm{~mm}$ and a tube with a diameter of $40 \mathrm{~mm}$ (Figure 2). The distance from the sensor to the end surface of the tube was chosen taking into account the directional pattern of the sensor, in particular, that the sensor readings are calculated based on the infrared radiation flux falling at an angle of 35 degrees relative to the sensor axis (Figure 3 ). The length was $20 /(2 \tan (35 / 2))=31.7 \mathrm{~mm}$.

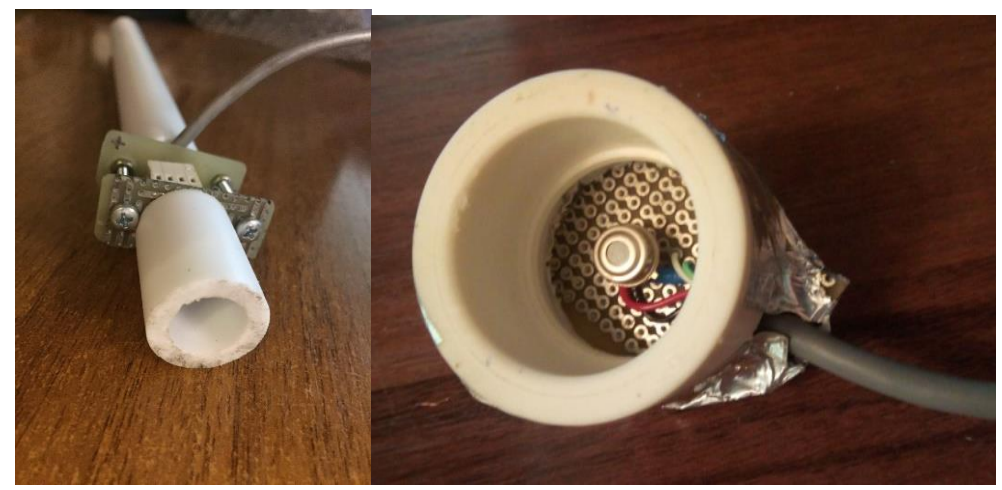

a

b

Fig. 2. Temperature meter design: $\mathrm{a}$ - tube of $20 \mathrm{~mm}$; b - tube of $40 \mathrm{~mm}$. 


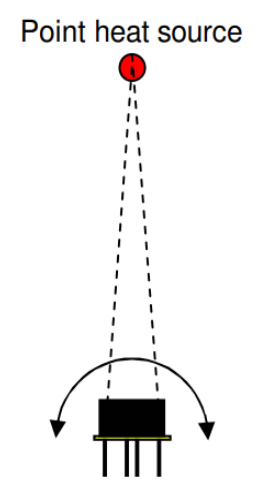

Rotated

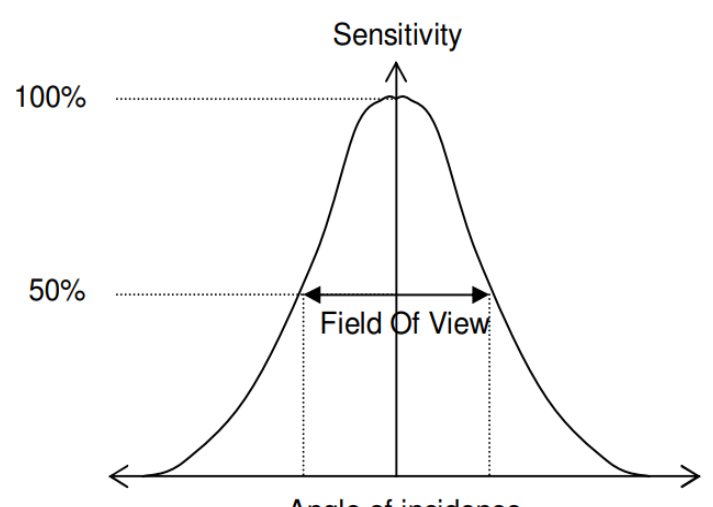

Angle of incidence

Fig. 3. Infrared sensor sensitivity diagram.

To test the operability of the temperature meter, a measuring channel was implemented based on a personal computer and special visual programming software. In the course of the study, it was found that the high accuracy and selectivity of the temperature sensor to the recorded infrared radiation generated by the area of the object's surface leads to a noticeable change in the sensor readings (+- 1 degree) with a slight change in its position $(+-5 \mathrm{~mm})$. This fact is typical for studying the temperature distribution over the surface of the human body. In addition, the presence of hair, including bristle, also distorts the sensor readings. In this regard, in examinations, it is preferable to use a sensor based on a narrow tube and to carry out the measurement in the area of the jugular fossa.

Another feature of non-contact temperature measurement in humans is the real registration of temperature from the skin surface, which leads to an underestimation. Comparison with JPD-FR302 and MC-341-RU specialized medical temperature meters confirmed this position. Moreover, these meters have a special mode for correcting readings. Therefore, for the MLX90614 sensor, correction factors were determined during the calibration, and the original sensor function was modified using a power polynomial of the second degree. The choice of correction factors is shown in Figure 4. During calibration, a JPD-FR302 medical thermometer operating in the "Body" mode was used as a reference meter.

$$
\begin{aligned}
& \mathrm{S}:=\left(\begin{array}{ccccccccc}
36.3 & 33.6 & 36.8 & 37.1 & 37.7 & 38.6 & 39.7 & 40.7 & 41.9 \\
32.85 & 36.5 & 33.8 & 34.4 & 34.8 & 35.2 & 36.25 & 37.1 & 38.15
\end{array}\right) \\
& \mathrm{x}_{\mathrm{i}}:=\mathrm{S}_{1, \mathrm{i}} \quad \mathrm{y}_{\mathrm{i}}:=\mathrm{S}_{0, \mathrm{i}} \quad \mathrm{z}_{\mathrm{i}}:=\mathrm{S}_{0, \mathrm{i}}-\mathrm{S}_{1, \mathrm{i}} \\
& \mathrm{v}_{0}:=\sum_{\mathrm{i}} \mathrm{y}_{\mathrm{i}} \quad \mathrm{v}_{1}:=\sum_{\mathrm{i}}\left(\mathrm{y}_{\mathrm{i}} \cdot \mathrm{x}_{\mathrm{i}}\right) \quad \mathrm{v}_{2}:=\sum_{\mathrm{i}}\left[\mathrm{y}_{\mathrm{i}} \cdot\left(\mathrm{x}_{\mathrm{i}}\right)^{2}\right] \\
& \mathrm{w}_{0,0}:=\mathrm{n} \quad \mathrm{w}_{0,1}:=\sum_{\mathrm{i}} \mathrm{x}_{\mathrm{i}} \quad \mathrm{w}_{1,0}:=\mathrm{w}_{0,1} \\
& \mathrm{w}_{0,2}:=\sum_{\mathrm{i}}\left(\mathrm{x}_{\mathrm{i}}\right)^{2} \quad \mathrm{w}_{2,0}:=\mathrm{w}_{0,2} \quad \mathrm{w}_{1,1}:=\mathrm{w}_{0,2} \\
& \mathrm{w}_{1,2}:=\sum_{\mathrm{i}}\left(\mathrm{x}_{\mathrm{i}}\right)^{3} \quad \mathrm{w}_{2,1}:=\mathrm{w}_{1,2} \quad \mathrm{w}_{2,2}:=\sum_{\mathrm{i}}\left(\mathrm{x}_{\mathrm{i}}\right)^{4} \\
& \mathrm{kof}:=\mathrm{w}^{-1} \cdot \mathrm{v} \quad \mathrm{kof}=\left(\begin{array}{c}
292.143 \\
-15.182 \\
0.226
\end{array}\right) \quad \mathrm{g}(\mathrm{p}):=\operatorname{kof}_{0}+\mathrm{kof}_{1} \cdot \mathrm{p}+\mathrm{kof}_{2} \cdot \mathrm{p}^{2}
\end{aligned}
$$

Fig. 4. Calculation of infrared sensor correction factors. 
Thus, the use of a tube of fixed length and radius in the design of the developed noncontact temperature meter makes it possible to minimize the error associated with the different distance of the sensor from the skin when the driver independently measures the temperature due to the limitation of the observation area. The use of correction coefficients of the calibration function allows taking into account the peculiarities of the choice of the temperature measurement point.

\subsection{Module for measuring tremor}

In addition to alcohol, a variety of psychoactive substances can affect the ability to drive. Their groups differ both in different composition and in different mechanisms and effects of exposure to a man - from activating to hallucinogenic and sedative. Identification of the entire spectrum of psychoactive substances (opiates, methadone, hemp, cocaine, methamphetamine, amphetamine, butyrate, hallucinogens, sedative-hypnotics, etc.) by laboratory methods is impossible in the express examination mode. Therefore, the task of identifying indirect signs of intoxication or its consequences is urgent.

One of the important nonspecific signs of a state of alcoholic or toxic intoxication is trembling of the fingers [10]. We have developed a hardware-software module for measuring tremor.

The hardware part of the module includes (Figure 5) a measuring cell, a probe, a protection and interface unit. The hardware part of the module is connected to the peripheral controller. The software part of the module is a set of procedures and functions implemented on the basis of peripheral and central controllers.

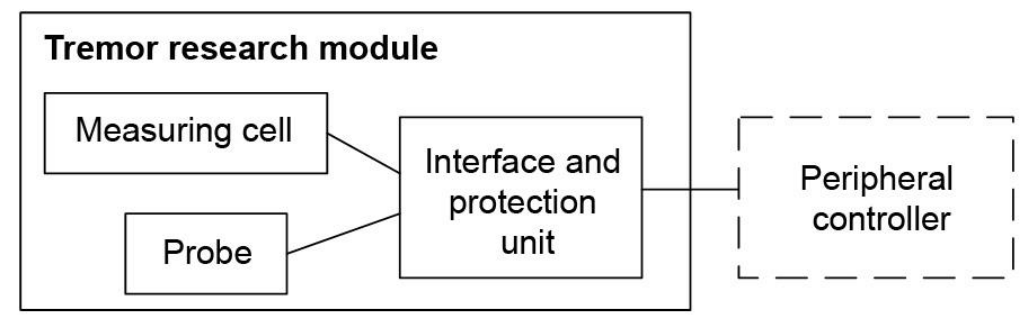

Fig. 5. The structure of the hardware part of the tremor research module.

The measuring cell (Figure 6, a) is made of $4 \mathrm{~mm}$ thick duralumin sheet. The cell has three holes with a diameter of $10 \mathrm{~mm}, 7 \mathrm{~mm}, 5 \mathrm{~mm}$, as well as an annular cavity $3.5 \mathrm{~mm}$ thick and an outer diameter of $37 \mathrm{~mm}$. With the help of screw terminals, two additional independent contacts are arranged at the extreme points of the annular cavity. The probe is a metal rod $1 \mathrm{~mm}$ in diameter with a dielectric handle. The interface and protection block is designed to protect the contacts of the peripheral controller from static electricity and to transmit a signal between the peripheral controller, probe and measuring cell.

The hardware part of the assembled model of the tremor measuring module is shown in Figure 6,b.

Instructions for taking the tremor assessment test are displayed on the touchscreen display on the subject's control panel. The driver is instructed to alternately place the probe into the holes of the measuring cell of different diameters, if possible without touching the walls of the hole with the probe. Each touch of the probe to the walls of the measuring cell is fixed and used to form tremor parameters. The presence of an annular cavity in the measuring cell makes it possible to record not only static, but also dynamic tremor that occurs when performing a movement - holding a probe inside the ring. 


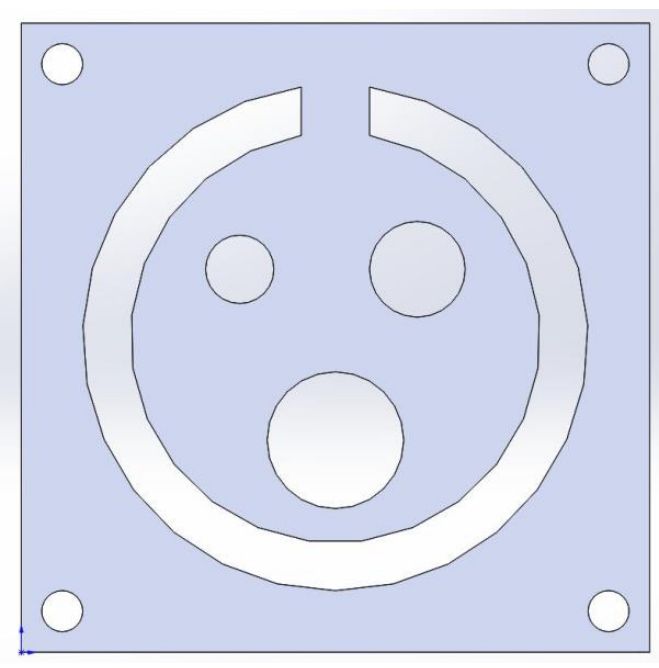

a

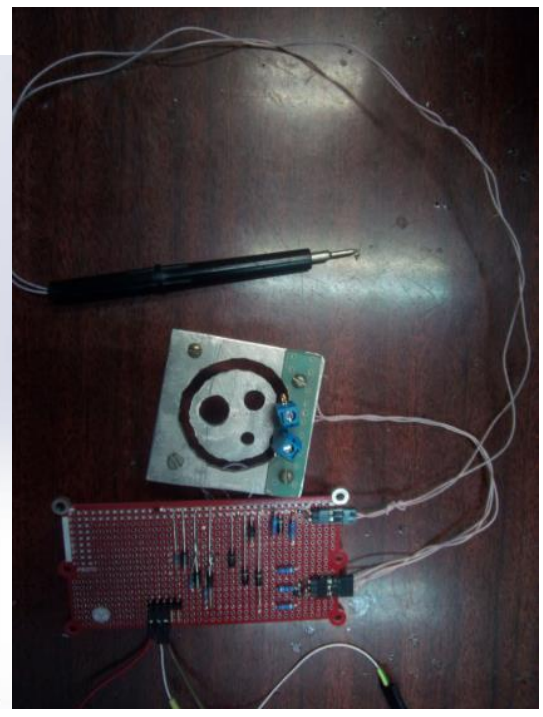

b

Fig. 6. Module for studying tremor: a - measuring cell; $b$ - module model.

Assessment of tremor parameters allows identifying nonspecific signs of intoxication with psychoactive substances and sending the driver for additional examination.

\subsection{Complex indicators of the functional and psycho-emotional state of the driver}

To study the functional and psychoemotional state of a person, to assess the level of fatigue, stress and adaptive reserves in general, indicators of variability of physiological processes are widely used [11]. R.M. Baevsky developed the concept of the possibility of using the circulatory system as an indicator of the adaptive reactions of the whole organism [12]. In this case, the instrument for assessing the functional state of the body is the heart rate variability (HRV).

Nowadays, a number of standard complex indicators of heart rate variability (indicator of activity of regulatory systems (IARS), stress index, triangular index, etc.) used to assess the state of a person are widely used. However, in the case of the automated system under consideration, the use of these indicators with acceptable accuracy is limited by the observation time, which requires the creation of specialized criteria.

One of the key requirements for the system being developed was to reduce the time for conducting pre-trip examination, which is necessary in a situation of a mass examination (admission to start the shift for the drivers of public transport). Therefore, the procedure for registering heart rate parameters was combined with the procedure for measuring blood pressure. The sensor, which registers the pulsation in the occlusal cuff, transmits information about the duration of 100 consecutive cardio intervals of the test subject to the peripheral controller. These data are used to detect signs of arrhythmia and to assess parameters of heart rate variability.

According to the results of the analysis of the series of cardio intervals, the following signs of heart rhythm disturbances can be distinguished:

1. Paroxysms of sinus tachycardia - the presence of episodes of sudden and short-term (20-30 s) increase in heart rate of more than 120 beats $/ \mathrm{min}$.

2. Sustained ventricular tachycardia - 100 beats/min for more than $30 \mathrm{~s}$. 
3. Sinus bradycardia - pulse below 50 beats $/ \mathrm{min}$.

4. Failure of the sinoatrial node - cases (more than 3-4 cases within 3 minutes) of an increase in the duration of the next cardio interval relative to the average CI of previous CIs by more than $125 \%$, i.e. if, with an average interval of $0.75 \mathrm{~s}$, the next interval is $1.7 \mathrm{~s}$, this is a suspicion of a sinoatrial node failure.

The index of sympathicoadrenal tone (SAT) [13] and the index of differences of consecutive cardio intervals (pNN50\%) [14] were chosen as the basic indicators for assessing the functional and psychoemotional state, providing a reliable assessment with a limited time interval of observation.

The index of sympathicoadrenal tone, reflecting the stabilization of the heart rhythm, i.e. decrease in variability, is determined by the modified formula

$$
S A T=\frac{A m o \cdot \operatorname{meanRR}}{5 \cdot S D Q},
$$

where Amo - the amplitude of the mode of the durations of the cardio intervals, meanRR - the mean value of the cardio interval in the sample under consideration, SDa the standard deviation of the durations of the cardio intervals from the mean absolute value.

The pNN50\% index, approved by the standard of the European Cardiological Community, is an indicator of the prevalence of the parasympathetic component of the regulation of the heart rate over the sympathetic one, and its decrease characterizes a high level of stress.

Table 2 shows the critical levels for SAT and pNN50\%.

Table 2. Critical levels of HRV indicators.

\begin{tabular}{|l|l|l|}
\hline & $1^{\text {st }}$ critical level & $2^{\text {nd }}$ critical level \\
\hline SAT & $>1200$ & $>1800$ \\
\hline pNN50\% & $<2.5 \%$ & $<1 \%$ \\
\hline
\end{tabular}

The algorithm for interpreting heart rate variability indicators can be formulated as follows:

- upon confirmation of exceeding the 1st critical level, the driver can be admitted to the shift conditionally.

- in the presence of two conditional admissions, the driver cannot be allowed to the work shift; he is advised to see a doctor.

- upon confirmation of exceeding the 2 nd critical level by any of the indices, the driver cannot be allowed to the work shift.

All indicators characterizing the condition of the driver are transferred and stored in the database on the doctor's computer. The negative dynamics of SAT and pNN50\% indices over several days indicates the accumulation of fatigue and depletion of the body, which requires measures to optimize the work and rest regimen.

\section{Conclusion}

The developed pre-trip control system measures a set of indicators of the driver's functional state: blood pressure; body temperature; the amount of alcohol in the exhaled air; tremor indicators; signs of arrhythmia and indicators of heart rate variability. The user identification unit allows additional verification of the identity of the person undergoing examination based on the processing of the video stream. The proposed algorithms for assessing the condition of drivers implement not only the principle of strict admission/not admission to the trip when, for example, the critical level of body temperature or blood 
pressure is exceeded, but also allow detecting nonspecific signs of drug intoxication, fatigue or stress.

The system allows reducing the time of pre-trip examination compared to a conventional medical examination and increasing its objectivity in comparison with known telemedicine systems due to the presence of a modified channel of increased accuracy for contactless temperature measurement and a tremor measurement module, as well as the use of complex indicators of the functional and psycho-emotional state of the driver in the formation of diagnostic conclusions.

\section{References}

1. 2018 Global status report on road safety 2018. Violence and Injury Prevention (World Health Organization)

2. 2014 On the approval of the Procedure for conducting pre-shift, pre-trip and postshift, post-trip medical examinations: Order of the Ministry of Health of the Russian Federation of December 15

3. Federal Law of July 29, 2017 N 242-FZ "On amendments to certain legislative acts of the Russian Federation on the application of information technologies in the field of health protection"

4. Kho J, Gillespie N, Martin-Khan M 2020 A systematic scoping review of change management practices used for telemedicine service implementations. BMC Health Services Research 10.1186/s12913-020-05657-w

5. Naweed Anjum \& Chapman Janine 2019 Good Practice in the Management of Rail Driver Health and Wellbeing Guideline

6. Melnik O V, Nikiforov M B, Demidova K A, Ustyukov D I 2017 Defense Technology Journal (Moscow) p 77

7. Muratov Y R, Nikiforov M B, Tarasov A S, Skachkov A M 2019 Advances in Neural Computation, Machine Learning, and Cognitive Research. III Selected Papers from the XXI International Conference on Neuroinformatics (Springer Nature Switzerland AG 2020) p 106

8. Sergeeva A D, Savin A V, Sablina V A, and Melnik O V 2019 8th Mediterranean Conference on Embedded Computing (MECO-2019) Proceedings - Research Monograph (Budva, Montenegro) p 632

9. Grinchenko N N, Dudko I S, Tarasov A S, Tarasova V Yu, Ustyukov D I 2019 Software tools for finding matches in a collection of images. Certificate of state registration of a computer program No. 2019616027

10. Aksenova-Sorokhtey Yu N, Baranovskaya E A, Kuzmina O L, and Makhanek A B 2018 Russian journal of criminology 12(3) 375

11. Melnik O V 2018 7th Mediterranean Conference on Embedded Computing (MECO2018) Proceedings - Research Monograph (Budva, Montenegro) p 537

12. Baevsky R M, Berseneva A P 1997 Evaluation of adaptive capacity of the organism and the risk of disease (Moscow: Medical) p 265

13. Kaplan A Ya 1999 Journal of Higher Nervous Activity 48(6) 345

14. 1996 Task Force of the European Society of Cardiology and the North American Society of pacing and electrophysiology. Eur. Heart J. 17354 